\title{
Association between tooth loss and overweight/obesity among Brazilian adults: the Pró-Saúde Study
}

\section{Luciane Maria PILOTTO(a) Roger Keller CELESTE(a) Eduardo FAERSTEIN ${ }^{\text {(b) }}$ Sonia Maria Blauth de SLAVUTZKY(a)}

(a) Department of Preventive and Social Dentistry, School of Dentistry, Universidade Federal do Rio Grande do Sul - UFRGS, Porto Alegre, RS, Brazil.

(b)Department of Epidemiology, Institute of Social Medicine, Universidade Estadual do Rio de Janeiro - UERJ, Rio de Janeiro, RJ, Brazil.

Declaration of Interests: The authors certify that they have no commercial or associative interest that represents a conflict of interest in connection with the manuscript.

Corresponding Author:

Luciane Maria Pilotto

E-mail: lutipilotto@yahoo.com.br

DOI: 10.1590/1807-3107BOR-2014.vol28.0032 Epub XXX XX, 2014

Submitted: Jul 30, 2013

Accepted for publication: May 06, 2014

Last revision: Jul 15, 2014

\begin{abstract}
The aim of this study was to evaluate the association between tooth loss and overweight/obesity in an adult Brazilian population. It is a cross-sectional study comprising 3,930 adults [1,744 men and 2,186 women; median age of $40 \mathrm{y}$ (ranging 20-59); $16.9 \%$ obese; $7.3 \%$ almost all or all teeth missing]. Data were collected using a selfadministered questionnaire for tooth loss (4 categories), diet, access and use of health services, socioeconomic factors, health habits and behaviors, demographics and anthropometric measurements. Multiple ordinal logistic regressions were performed. In comparison with adults with BMI $<25 \mathrm{~kg} / \mathrm{m}^{2}$, the overweight $\left(\mathrm{BMI} \geq 25\right.$ and $\left.<30 \mathrm{~kg} / \mathrm{m}^{2}\right)$ and obese individuals (BMI $\geq 30 \mathrm{~kg} / \mathrm{m}^{2}$ ) showed a greater odds of tooth loss ( $\mathrm{OR}=1.6,95 \% \mathrm{CI} 1.4-1.9$ and $\mathrm{OR}=2.1,95 \% \mathrm{CI} 1.8-2.5$, respectively). After adjusting for potential confounders, overweight and obesity showed no statistically significant associations with tooth loss, with $\mathrm{OR}=0.8$ and $\mathrm{OR}=0.9$, respectively. The results of this study are consistent with the hypothesis that the association between overweight/obesity and tooth loss can be explained by known, common risk factors.
\end{abstract}

Keywords: Tooth Loss; Obesity; Adult; Risk Factors.

\section{Introduction}

Obesity and dental caries are chronic diseases. Both conditions are important public health problems worldwide, and both cause adverse health outcomes. ${ }^{1,2}$ In 2008, almost two-thirds of deaths worldwide were due to chronic diseases, and these diseases have shown worrisome trends, since they affect a large percentage of the world population, and are appearing earlier in life. ${ }^{3}$ Dental caries is a major cause of tooth loss followed by periodontal disease. ${ }^{4}$

Unhealthy diets are a major cause of chronic non-communicable diseases, such as obesity and dental caries. ${ }^{1}$ The consumption of processed foods rich in sugars and fats constitutes an important risk factor for obesity. ${ }^{3}$ A diet rich in refined sugars is the most important risk factor for dental caries. ${ }^{5}$ Some authors have suggested that eating habits might be a common risk factor for dental caries and obesity, thus explaining their coexistence. ${ }^{6,7}$ Other authors, after controlling for confounding factors, such as socioeconomic status, found no association between these problems. ${ }^{8}$ Yet others found that obese people have more dental caries and tooth loss. ${ }^{2}$ Inverse associations were also found. These indicated that overweight chil- 
dren had fewer decayed, missing or filled teeth than normal-weight children, ${ }^{9}$ and that older adults who had a smaller number of teeth also had a higher body mass index (BMI). ${ }^{10}$ Systematic reviews investigating the relationship between tooth loss and obesity were inconclusive and could not specify the direction or the mechanisms of the association..$^{11,12}$

Despite the large number of studies evaluating the relationship between tooth loss and obesity, the evidence regarding the direction and nature of this relationship has proved inconclusive, and it is unclear whether a causal relationship exists. Many epidemiological studies have shown that there is a group of common risk factors related to many chronic diseases. ${ }^{3}$ In contrast, some authors have suggested a relationship between obesity and tooth loss, insofar as individuals with obesity tend to have less saliva flow, which can lead to dental caries, thus mediating the association between obesity and tooth loss. ${ }^{13}$ Other authors have found no positive association. ${ }^{14}$ Furthermore, a weak association between obesity and periodontal diseases has been reported, thereby also mediating the relationship between obesity and tooth loss. ${ }^{15}$ Our hypothesis is that the association between these two problems, among adults, is mainly caused by common risk factors. The association could be the result of confounding factors. Hence, the objective of this study was to assess the association between overweight/obesity and tooth loss in an adult Brazilian population.

\section{Metodology}

\section{Design and Study Population}

This cross-sectional study used data obtained from Phase I (1999) of the Pró-Saúde study, a longitudinal investigation that included civil servants at a university in Rio de Janeiro, Brazil. The details of this longitudinal study have been published elsewhere. ${ }^{16}$

The source population consisted of 4,601 civil servants. The study was planned as a census of all eligible civil servants (registered). A total of 118 employees were deemed ineligible because they were on leave from graduate school, were on unpaid leave, had transferred out to other institutions or were retired. Thus, the eligible population consisted of 4,483 employees. Another 453 employees were not interviewed, either because they did not want to take part or for other reasons. This study was approved by the Research Ethics Committee of the Hospital Universitário Pedro Ernesto, RJ, on May 10, 1999.

\section{Instruments and Measures}

The data were collected in the workplace, using a self-administered questionnaire that had structured questions, and that was developed specifically for the longitudinal study. After completing the questionnaire, measurements were taken by trained personnel for weight and height, according to the technique described by Habicht (1974). Methods to guarantee the quality of the information were used.

The outcome variable was self-reported tooth loss, collected by the question: "Over time, many people lose some or all of their teeth. Which of the following best corresponds to the number of teeth that you have lost?" The response options were: 1- "I have not lost any teeth"; 2- "I have lost one or a few teeth"; 3"I have lost several teeth"; and 4- "I have lost most or all of my teeth."

The main exposure factors under analysis were obesity and overweight, and were calculated using weight and height measurements. Weight $(\mathrm{kg})$ and height $(\mathrm{m})$ were measured with the participants wearing light clothes and no shoes. Trained nutritionists used Kratos-Cas (model LINEA, Taboão da Serra, Brazil) portable electronic scales, with a $150 \mathrm{~kg}$ capacity and $50 \mathrm{~g}$ precision, and a measuring tape made of non-elastic material, with a $150 \mathrm{~cm}$ capacity and $0.1 \mathrm{~cm}$ precision, fixed with the aid of a plumb to a wall with no baseboard, according to standardized methods. Adults were classified as underweight $\left(\mathrm{BMI}<18.5 \mathrm{~kg} / \mathrm{m}^{2}\right)$, normal weight (BMI $\geq 18.5$ and $\left.<25 \mathrm{~kg} / \mathrm{m}^{2}\right)$, overweight $\left(\mathrm{BM} \mathrm{I} \geq 25\right.$ and $\left.<30 \mathrm{~kg} / \mathrm{m}^{2}\right)$ or obese $\left(\mathrm{BMI} \geq 30 \mathrm{~kg} / \mathrm{m}^{2}\right)$, according to the cut-offs of the $\mathrm{WHO}{ }^{17}$ The categories of underweight and normal weight were grouped for the analysis, because of the small number of underweight individuals. The respondents reported their weight at age 20 on the questionnaire; the BMI at that age was then calculated using the respondent's current height. Weight stability was obtained by comparing changes in BMI categories (normal/overweight/ obesity) at the age of 20 and at the current age. 
Other independent variables were grouped into blocks: Model 1-Demographic variables: sex and age; Model 2-Diet: variables on dietary intake of fruits, deep-fried foods and vegetables ("How often do you eat__? - Never/once a month, 1 to 3 times a month, 1 to 3 times a week, 4 to 6 times a week, daily); Model 3-Health services: data on the frequency of visits to the dentist (never/only when in trouble - Less than every 2 years, every 2 years, every year) and having health insurance; Model 4-Behavioral markers: alcohol consumption ("Did you have any alcoholic drink in the last 2 weeks? - Yes/no"), smoking (smoker, exsmoker, never smoked), physical activity ("Did you practice any physical activity in your leisure time in the last 2 weeks? - Yes/no") and weight stability as of 20 years of age; and Model 5-Socioeconomic variables: educational level and equivalised household income. Household income was calculated as a continuous variable using the midpoint of each reported income category (7 categories) as the income, and then equivalised using the square root of the number of residents. This value was divided by the value of the minimum wage at the time of the survey ( $R$ \$ 136.00, equivalent to US\$127). Educational level was classified as incomplete elementary school, complete elementary school, high school, and university/ higher. Age was entered into the regression models as a continuous variable.

\section{Data Analysis}

The data are presented in a bivariate table to analyze associations between the outcome and the main exposures. Multiple regression analysis was performed, fitting partial proportional ordinal logistic models according to Hosmer and Lemeshow. ${ }^{18}$ Five variables violated the proportional odds assumption (smoking, education, visits to the dentist, age, and deep-fried food consumption). These variables were tested for all covariates ( $\alpha$ was set to $1 \%$ significance), according to the Brant test. Were such an assumption violated, there would be three sets of odds ratios, one set for each cut-off point of our outcomes. Therefore, to avoid extensive tables, we chose to present only the odds ratios of the main exposures, since one set of odds ratio could hold the (partial) proportional odds assumption.
For the purpose of evaluating the impact of similar, and perhaps collinear, variables, we built one model for each previously described block, keeping only those variables with $p<0.20$ as the final model. The fit of the models was evaluated according to two main parameters: Bayesian information criteria and adjusted pseudo- $R^{2}$. The best model, Final Model, was also assessed with a goodness-of-fit test, as described elsewhere in the literature. ${ }^{18}$ Basically, we ran three ordinary logistic regressions after dichotomizing the variable at all three cut-off-points. Since the HosmerLemeshow goodness-of-fit test was acceptable for all of the regressions, it was also considered acceptable for the ordinal logistic regression. All of the analyses were performed using Stata software, version 11.2 (Stata Corporation, College Station, USA).

\section{Results}

The final sample for this analysis included 3,930 employees with an average age of $40 \mathrm{y}(\mathrm{SD}=8.02)$, $56 \%$ women and $44 \%$ men. The weight stability variable, as of age 20 , had the largest percentage (5\%) of missing values, with 200 individuals who did not complete the questionnaire entirely. The final model included a sample of 3,341 subjects ( $14.9 \%$ losses). Of these, 7.3\% reported missing all or most of their teeth, $19.3 \%$ as having lost many teeth, and $50.9 \%$ as having lost one or a few teeth (Table 1).

The average income was 9.4 minimum wages (MW) $(\mathrm{SD}=6.20)$, insofar as participants with no missing teeth had an average income of $12.3 \mathrm{MW}$, and individuals with all or almost all of their teeth missing had an average income of 5.95MW $(p<0.01)$. Individuals with all or most of their teeth missing had an average age of 49 years, and those with no teeth missing were 34 years old, on average $(p<0.01)$. Moreover, $36 \%$ of the employees had a high school degree and $41 \%$ had a university degree or higher, and, among these groups, only $6 \%$ and $1 \%$, respectively, reported having lost all or most of their teeth. Individuals with incomplete elementary school education had a 50 -fold greater chance of having all of their teeth missing, compared with participants with a university education or higher $(\mathrm{OR}=53.0, \mathrm{CI} 95 \%$ 29.8-94.3).

At age $20,90 \%$ of the sample had a normal BMI, $8 \%$ were overweight, and $2 \%$ were obese, whereas 
Table 1. Relative and absolute frequencies of BMI variable according to tooth loss category

\begin{tabular}{lccccc}
\hline & \multicolumn{3}{c}{ Tooth loss } \\
\cline { 2 - 5 } & None & One or Few & Many & Almost All or All & Total \\
\hline BMl categorized & & & & & \\
Normal/Low & $28.0(512)$ & $51.4(941)$ & $15.1(277)$ & $5.6(102)$ & $100(1,832)$ \\
Overweight & $18.9(268)$ & $50.8(720)$ & $22.9(324)$ & $7.4(105)$ & $100(1,417)$ \\
Obese & $15.2(100)$ & $50.0(328)$ & $23.0(151)$ & $11.7(77)$ & $100(656)$ \\
Total $(\mathrm{n})$ & $22.5(880)$ & $50.9(1,989)$ & $19.3(752)$ & $7.3(284)$ & $100(3,905)$ \\
\hline
\end{tabular}

Normal/Low: BMI $<25 \mathrm{~kg} / \mathrm{m}^{2}$; Overweight: BMI $\geq 25 \mathrm{~kg} / \mathrm{m}^{2}$ and $<30 \mathrm{~kg} / \mathrm{m}^{2} ;$ Obese: BMI $\geq 30 \mathrm{~kg} / \mathrm{m}^{2}$

Chi-square for heterogeneity: $p<0.01$

these percentages at the time of the study were $47 \%$, $36 \%$ and $17 \%$, respectively. Among the participants, $51 \%$ remained in the normal category, $36 \%$ moved into the overweight category, and $13 \%$ became obese.

Several models were tested to examine the association between tooth loss and overweight/obesity (Table 2). Obesity/overweight was represented by only one set of odds ratio, because this variable did not violate any assumptions. Analyses of the unadjusted model showed a greater chance of tooth loss for overweight individuals and obese people. However, this association lost significance when adjusted for confounding variables, mainly demographic (Pseudo $\mathrm{R}^{2}=13 \%$, BICs, 8114.324). The dietary variables had the worst fit $(\mathrm{BIC}=9249.659)$, constituting the worst adjusted model (Pseudo $\mathrm{R}^{2}=2 \%$ ). The final model included all potentially confounding variables, apart from sex and fruit consumption, which were not statisti-

Table 2. Odds ratios of the regression models for outcomes: normal $/$ low $\left(\mathrm{BMI}<25 \mathrm{~kg} / \mathrm{m}^{2}\right)$, overweight $\left(\mathrm{BMI} \geq 25 \mathrm{~kg} / \mathrm{m}^{2}\right.$ and $\left.<30 \mathrm{~kg} / \mathrm{m}^{2}\right)$ and obese $\left(\mathrm{BMI} \geq 30 \mathrm{~kg} / \mathrm{m}^{2}\right)$

\begin{tabular}{lccc}
\hline & \multicolumn{3}{c}{ Tooth loss } \\
& \multicolumn{3}{c}{ Odds Ratio (C195\%) } \\
& $\begin{array}{l}\text { Normal/ } \\
\text { Low }\end{array}$ & Overweight & Obesity \\
\hline Unadjusted Model & 1.00 & 1.64 & 2.12 \\
& & $(1.44-1.88)$ & $(1.79-2.51)$ \\
Model 1: & 1.00 & 1.24 & 1.32 \\
Demographic variables & & $(1.08-1.42)$ & $(1.11-1.57)$ \\
Model 2: Dietary & 1.00 & 1.63 & 2.07 \\
variables & & $(1.42-1.86)$ & $(1.74-2.46)$ \\
Model 3: Health & 1.00 & 1.58 & 1.90 \\
services & & $(1.38-1.80)$ & $(1.60-2.26)$ \\
Model 4: Health & 1.00 & 0.80 & 1.09 \\
behaviors & & $(0.57-1.10)$ & $(0.78-1.53)$ \\
Model 5: & 1.00 & 1.35 & 1.53 \\
Socioeconomic variables & & $(1.18-1.55)$ & $(1.28-1.83)$ \\
Final Model & 1.00 & 0.80 & 0.86 \\
& & $(0.57-1.12)$ & $(0.60-1.23)$ \\
\hline
\end{tabular}

cally significant within their block of variables. In the final model, the odds ratio for the category of 'increasing tooth loss' was not significant either for overweight or obesity $\left(\mathrm{BIC}=6590.952, \mathrm{R}^{2}=20 \%\right.$ ). We also tested for interactions among sex, weight gain and tooth loss, as well as among age, weight gain and tooth loss. These interactions were significant for the unadjusted model, but lost significance in the final model, and thus were removed ( $p>0.05)$.

\section{Discussion}

In our study, we observed an association between obesity and tooth loss of a reasonable magnitude among adults, in the unadjusted model. Obese individuals had roughly twice the chance of having high levels of tooth loss compared with participants of normal weight. However, after adjustment, this association washed out. These results are consistent with the hypothesis that they share common risk factors.

Most studies investigating the relationship between these conditions have been conducted with children or adolescents. ${ }^{2,7,8,9,19,20,21}$ Some have been conducted with elderly populations, ${ }^{10,22}$ but few with workingage adults. ${ }^{6,23,24}$ Our findings are consistent with those of other studies with children, ${ }^{7,8,19,20,25}$ adults $^{24}$ and the elderly, ${ }^{26}$ which also found no association between obesity and dental caries after adjusting for confounding variables. However, some investigations with children and adolescents ${ }^{2,21}$ and with adults $^{6}$ and the elderly, ${ }^{10,22}$ have found an association among these individuals, even after controlling for some confounding factors.

In our study, no variable alone could explain the relationship between obesity and tooth loss. The loss of statistical significance occurred after controlling for a broad set of variables, among which age and 
weight stability were the most important. An important variable in our model was weight stability as of age 20 . We believe that this variable can capture the lifestyle of people over the course of their life better than their lifestyle currently. Weight change is associated with several factors, including dietary habits and physical activity. ${ }^{27}$ Nonetheless, whether weight gain based on self-reported data is a good marker of lifestyle remains to be investigated.

The limitations of this study include its cross-sectional design and use of self-reported tooth loss and self-reported dietary data. Regarding self-reported tooth loss, its validity has been shown using clinical examinations as the gold standard..$^{28}$ Any method for evaluating dietary intake is flawed in some way, and there is no gold standard for nutritional questionnaires; nevertheless, data for evaluating food consumption and nutritional intake in a population should be considered. ${ }^{29}$ The lack of data related to sugar consumption in this study does not constitute a strong limitation, because the absolute intake of fat and sugar are strongly correlated..$^{30}$ There are restrictions in extrapolating our data to the general population of adult workers. Strictly speaking, inferential

\section{References}

1. World Health Organization. Global strategy on diet, physical activity and health [homepage]. Geneva: World Health Organization; 2004 [cited 2011 Aug 10]. Available from: http:// apps.who.int/gb/ebwha/pdf_files/WHA57/A57_R17-en.pdf.

2. Marshall TA, Eichenberger-Gilmore JM, Broffitt BA, Warren JJ, Levy SM. Dental caries and childhood obesity: roles of diet and socioeconomic status. Community Dent Oral Epidemiol. 2007 Dec;35(6):449-58.

3. World Health Organization. Global status report on noncommunicable diseases 2010. Geneva: World Health Organization; 2011 [cited 2011 Aug 14]. Available from: http://www. who.int/nmh/publications/ncd_report_full_en.pdf.

4. Jovino-Silveira RC, Caldas Jr AF, Souza EH, Gusmão ES. Primary reason for tooth extraction in a Brazilian adult population. Oral Health Prev Dent. 2005;3(3):151-7.

5. Moynihan P, Petersen PE. Diet, nutrition and the prevention of dental diseases. Public Health Nutr. 2004 Feb;7(1A):201-26.

6. Johansson I, Tidehag P, Lundberg V, Hallmans G. Dental status, diet and cardiovascular risk factors in middle-aged people in northern Sweden. Community Dent Oral Epidemiol. 1994 Dec;22(6):431-6. statistics are designed for random samples, but, in our case, we had a census of university workers, which was used as a non-random sample of general workers. However, we believe that the associations remain valid and accurately reflect current standards for the urban middle class, with reasonable heterogeneity.

\section{Conclusion}

We can conclude that the relationship between tooth loss and overweight/obesity is confounded by common risk factors that interfere with both conditions. Our findings suggest that programs addressing common risk factors should be encouraged. These results underscore the need for integration among health professionals, such as dentists, medical doctors and nutritionists, to promote health and to reduce oral and nutritional problems. Research to evaluate whether improvements in diet and lifestyle can reduce obesity and dental caries should be encouraged.

\section{Acknowledgments}

The authors have no financial relationships relevant to this article to disclose.

7. Hong L, Ahmed A, McCunniff M, Overman P, Mathew M. Obesity and dental caries in children aged 2-6 years in the United States: National Health and Nutrition Examination Survey 1999-2002. J Public Health Dent. 2008 Fall;68(4):227-33.

8. Alves LS, Susin C, Damé-Teixeira N, Maltz M. Overweight and obesity are not associated with dental caries among 12-year-old South Brazilian schoolchildren. Community Dent Oral Epidemiol. 2013;41(3):224-31.

9. Macek MD, Mitola DJ. Exploring the association between overweight and dental caries among US children. Pediatr Dent. 2006 Jul-Aug;28(4):375-80.

10. Hilgert JB, Hugo FN, de Sousa ML, Bozzetti MC. Oral status and its association with obesity in Southern Brazilian older people. Gerodontology. 2009 Mar;26(1):46-52.

11. Kantovitz KR, Pascon FM, Rontani RM, Gavião MB. Obesity and dental caries: a systematic review. Oral Health Prev Dent. 2006;4(2):137-44.

12. Hooley M, Skouteris H, Boganin C, Satur J, Kilpatrick N. Body mass index and dental caries in children and adolescents: a systematic review of literature published 2004 to 2011. Syst Rev [Internet]. 2012 [cited 2013 Jul 25];1:57. 
doi: 10.1186/2046-4053-1-57. Available from: http://www. systematicreviewsjournal.com/content/1/1/57.

13. Flink H, Bergdahl M, Tegelberg A, Rosenblad A, Lagerlöf F. Prevalence of hyposalivation in relation to general health, body mass index and remaining teeth in different age groups of adults. Community Dent Oral Epidemiol. 2008 Dec;36(6):523-31.

14. Powers PS, Holland P, Miller C, Powers HP. Salivation patterns of obese and normal subjects. Int J Obes. 1982;6(3):267-70.

15. Chaffee BW, Weston SJ. Association between chronic periodontal disease and obesity: a systematic review and metaanalysis. J Periodontol. 2010 Dec;81(12):1708-1724.

16. Faerstein E, Chor D, Lopes CS, Werneck GL. The Pro-Saude Study: general characteristics and methodological aspects. Rev Bras Epidemiol. 2005;8(4):454-66. Portuguese.

17. World Health Organization. Expert Committee on Physical Status. Physical status: the use and interpretation of anthropometry. Geneva: World Health Organization; 1995. WHO Technical Report Series, 854 [cited 2010 Jul 20]. Available from: http://whqlibdoc.who.int/trs/WHO_TRS_854.pdf.

18. Hosmer DW, Lemeshow S. Applied logistic regression. 2nd ed. New York: Wiley; 2000. 379 p.

19. Sheller B, Churchill SS, Williams BJ, Davidson B. Body mass index of children with severe early childhood caries. Pediatr Dent. 2009 May-Jun;31(3):216-21.

20. Mapengo MA, Marsicano JA, Garcia de Moura P, Sales-Peres A, Hobdell M, de Carvalho Sales-Peres SH. Dental caries in adolescents from public schools in Maputo, Mozambique. Int Dent J. 2010 Aug;60(4):273-81.

21. Larsson B, Johansson I, Hallmans G, Ericson T. Relationship between dental caries and risk factors for atherosclerosis in Swedish adolescents? Community Dent Oral Epidemiol. 1995 Aug;23(4):205-10.
22. Sheiham A, Steele JG, Marcenes W, Lowe C, Finch S, Bates $\mathrm{CJ}$, et al. The relationship among dental status, nutrient intake, and nutritional status in older people. J Dent Res. 2001 Feb;80(2):408-13.

23. Ostberg AL, Nyholm M, Gullberg B, Råstam L, Lindblad U. Tooth loss and obesity in a defined Swedish population. Scand J Public Health. 2009 Jun;37(4):427-33.

24. Bernardo CO, Boing AF, Vasconcelos FAG, Peres KG, Peres MA. Association between tooth loss and obesity in Brazilian adults: a population-based study. Rev Saude Publica. 2012 Oct;46(5):834-42.

25. Sánchez-Pérez L, Irigoyen ME, Zepeda M. Dental caries, tooth eruption timing and obesity: a longitudinal study in a group of Mexican schoolchildren. Acta Odontol Scand. 2010 Jan;68(1):57-64.

26. Andrade FB, Caldas Jr AF, Kitoko PM. Relationship between oral health, nutrient intake and nutritional status in a sample of Brazilian elderly people. Gerodontology. 2009 Mar;26(1):40-5.

27. Lewis CE, Jacobs DR Jr, McCreath H, Kiefe CI, Schreiner PJ, Smith DE, et al. Weight gain continues in the 1990s: 10-year trends in weight and overweight from the CARDIA study. Coronary Artery Risk Development in Young Adults. Am J Epidemiol. 2000 Jun 15;151(12):1172-81.

28. Unell L, Söderfeldt B, Halling A, Paulander J, Birkhed D. Oral disease, impairment, and illness: congruence between clinical and questionnaire findings. Acta Odontol Scand. 1997 Apr;55(2):127-32.

29. Salvo VL, Gimeno SG. Reproducibility and validity of a food frequency questionnaire. Rev Saude Publica. 2002 Aug;36(4):505-12. Portuguese.

30. Emmett PM, Heaton KW. Is extrinsic sugar a vehicle for dietary fat? Lancet. 1995 Jun 17;345(8964):1537-40. 